\title{
Two Shades of Cringe: Problems in Attributing Painful Laughter
}

\author{
Patrick Wöhrle
}

check for

updates

Citation: Wöhrle, Patrick. 2021. Two Shades of Cringe: Problems in Attributing Painful Laughter. Humanities 10: 99. https://doi.org/ 10.3390/h10030099

Academic Editor: Wieland Schwanebeck

Received: 15 May 2021

Accepted: 25 August 2021

Published: 28 August 2021

Publisher's Note: MDPI stays neutral with regard to jurisdictional claims in published maps and institutional affiliations.

Copyright: (C) 2021 by the author. Licensee MDPI, Basel, Switzerland. This article is an open access article distributed under the terms and conditions of the Creative Commons Attribution (CC BY) license (https:// creativecommons.org/licenses/by/ $4.0 /)$.
Lab for Research on Organization and Differentiation, Faculty of Arts, Humanities and Social Science, TU Dresden, 01062 Dresden, Germany; patrick.woehrle@tu-dresden.de

\begin{abstract}
This article aims to approach the phenomenon of cringe in four steps: First, from a sociological perspective, the distinction between shame and embarrassment is discussed and a working definition is developed that conceives of this difference as situational rather than essential. In a second step, this distinction will be used to examine more closely how the actors' self-representation is decomposed in the reality format Wife Swap and what role cringe-understood as "Fremdscham" or "vicarious embarrassment" - plays in this. Third, an explanation for the attractiveness of these formats is offered that draws on the concept of "flexible normalism" and further specifies the latent functions of these formats sociologically. Finally, with a look at current cringe comedy, it is elaborated that the use of cringe as made in Wife Swap is a very restricted and truncated variety of this phenomenon. Cringe in a comprehensive sense, meanwhile, turns out to be a reflexive resource based on an unresolved ambiguity of multiple and often intersecting attributions.
\end{abstract}

Keywords: shame; embarrassment; cringe; reality TV; presentation of self; social deviation; social theory

\section{Introduction}

A collapsing stage set during a speech by Theresa May, the tweet "\#Cofveve" by Donald Trump, a disastrously failed "high-five", a pushy quiz host coercing "little kisses" from children on camera, a middle-aged reporter unsuccessfully trying his hand at youth slang, casting shows in which contestants clearly overestimate themselves-the film clips, which are commented on in social media and video portals with a short, but emphatic, "Cringe!", are innumerable and of the most diverse nature. There have long been thousands of "cringe compilations" on the internet, and the most "cringeworthy" snippets are quickly going around the globe as digital memes. How to explain the strange popularity of these incidents and accidents? How can the manifold phenomena that the expression "cringe" refers to be grasped analytically in more detail? What social circumstances might foster the desire for cringe? Does this desire have a distinct social function? What are the cultural and media roots of this kind of humour?

For a media studies perspective interested in the forms and functions of "cringe" and "cringeworthy" moments, it is natural to refer to studies that have focused attention on a very related concept: awkwardness. In particular, the profound reflections of Kotsko (2010) and Middleton (2014) diagnosed an "awkward turn" in the media sphere, reaching from comedy television series just as Curb Your Enthusiasm or The Office to movies like There's Something About Mary and the growing genre of mockumentary, brilliantly performed by Sasha Baron Cohen (Borat). In these studies, the display of awkwardness appears as the primary means of a broader shift from realistic to self-reflective media formats, irritating both the viewer and the filmmaker and destabilizing the common modes of their relation. Awkwardness, then, is a media effect leading to altered forms of spectatorship and a critical self-assessment of documentary's taken-for-granted criteria-truth and authenticity. "Cringe" seems to be the youngest and wildest child of this alteration, as this wide-spread term also points to the breakdown of the viewer's expectations, followed by incredulous amazement over social failings, lost self-control or collapsing interaction. 
Without denying the validity of this approach in any way, the considerations presented here choose a different way of coming to grips with the phenomenon of cringe. They initially refrain from a more detailed examination of the media-spectator relation and a further use of the concept of awkwardness; instead, they focus on the sociological difference between shame and embarrassment. The reason for this approach is that sticking too narrowly to the concept of awkwardness can only partially answer the question of what actually constitutes cringe; saying that we cringe when we observe awkward behaviour is of little use if one is interested in the interactional conditions under which such an attribution is made in the first place. Moreover, as I try to show, a specification of cringe more closely aligned with the concepts of shame and embarrassment may provide more clarity in this regard.

In doing so, we also remain sensitive to the inconspicuous semantic shifts of these concepts, which can be revealed in-supposed-synonyms of cringe: in German, "cringe" is usually translated as "Fremdscham"; and in English, too, there is a synonym for cringe that uses an older etymology: vicarious embarrassment. By tying the connotative dimensions of these terms back to sociological interaction theory, we want to draw attention to a small but crucial difference: while "shame" denotes an individual and isolated feeling, "embarrassing" can be applied not only to a person's (mis-)behaviour, but also to situations that are collectively perceived as embarrassing. On the basis of these different attributions, I will argue that both the term "Fremdscham" and the term "vicarious embarrassment" - as important as they may be for a systematic approach to the phenomenon in question-only allow for a significantly truncated understanding of "cringe". As to be shown, the ideal type of such a truncated understanding can be traced in the dramaturgical structure of the reality format Wife Swap. By attributing cringeworthy situations to personal failures, such formats resolve the multidirectional tension of cringe at an early stage and convey an affectively stabilized self-assurance to the viewer. The full spectrum of cringe, however, only comes into play when there is no one to blame for the discomfort you feel and no one you can be vicariously embarrassed for. It is only such a constellation that leads to those awkward situations that Kotsko and Middleton analyse so thoroughly.

The argumentation I have just outlined is structured in detail as follows: In the first part, I will briefly discuss what characterizes feelings of shame and embarrassing situations from a sociological perspective and how such situations are dealt with socially (Scheff 2000). In the second part, I will discuss the dramaturgical setting of the series Wife Swap/Frauentausch to demonstrate what happens to embarrassing situations and corresponding coping strategies when they become the material of so-called reality TV. Third, I will provide a sociological explanation for the-counter-intuitive-popularity of these formats by drawing on the concept of "flexible normalism" developed by Jürgen Link (1996, 2004). In the final chapter, I will return to the questions posed at the outset. By carefully reflecting and narrowing the explanatory scope of my analysis, it becomes clear that "cringe" covers a much broader spectrum of phenomena than "Fremdscham" and "vicarious embarrassment" are able to express: "cringe" refers only to a nonspecific bodily discomfort and remains open to different modes of interpretation. In contrast, "Fremdscham" and "vicarious embarrassment" already contain social attributions that anticipate the (supposed) origins and responsibilities for this discomfort.

\section{Shame and Embarrassment-A Brief Sociological Account}

There is a large and still ongoing debate in psychology about the distinctness of shame and embarrassment. Previous work assumed that both terms denote negative selfevaluative emotions or, more precisely, negative "self-other-conscious" (Reddy 2008, p. 145) emotions and therefore refer to the same type of emotion, differing only in intensity (see Sabini et al. 2001, p. 104). This assumption has been challenged by an extensive catalogue of further differentiation criteria, which should allow for a clearer distinction. For example, there is an attempt to differentiate along the different standards that are violated, persona or ideal self-image (Babcock and Sabini 1990). Crozier (2014) provides a comprehensive 
overview of these criteria, ranging from the duration of the emotion in question to the nature of the violation, from the display of emotion to the degree of personal involvement. In the end, however, he concludes that in psychology, "no consensus has been reached on how shame and embarrassment differ" (Crozier 2014, p. 274) because each criteria specification breaks down at some point. For example, attempting to narrow the meaning of shame to moral issues related to the inner personal core, being "a global attack on the self" (Lewis 2008, p. 748), while embarrassment is seen as a more superficial and sporadic sensation, entails the problem that shame also encompasses aesthetic or socio-structural dimensions, while the experience of embarrassment can also be of "deep" moral quality for the individual.

From a sociolinguistic perspective, Krawczak (2018) has already pointed to a further problem of this distinction by taking a comparative look at different national language semantics of shame and embarrassment: in some speech communities, "shame" and "embarrassment" are clearly distinguishable, while in others, "the usage patterns associated with them [ ... ] seem to merge"; and often, according to Krawczak (2018, p. 464), these semantic deviations have their roots in deep-seated sociocultural patterns, which in one case contain a more individualistic and in the other a more collectivistic value orientation.

Given the difficulty of distinguishing these two concepts in psychological and sociolinguistic terms, it might be helpful to consult sociology more closely on this issue. Without claiming that a sociological approach can completely overcome the problems of distinction, I think it has one crucial advantage: in classical sociological thought, both embarrassment and shame are not located on the level of distinct emotional qualities, but rather on the level of highly incorporated social expectations. While shame as a moral phenomenon was left to philosophy, sociology focused on the body-related dimensions of shame and embarrassment and did so against a historical background: for Elias (2012), the entire process of Western civilization can be reconstructed as a process of "distancing the body". In this process, shame emerges as a central mechanism for transforming external constraints into internal discipline, and bodily actions and reactions are the main training ground for this kind of exercise: from table manners to the condemnation of spitting, from the hidden preparation of meat to bodily functions and gender norms, there are numerous areas in which strict and subtly nuanced self-control is increasingly socially expected; shame, in this sense, arises from the feeling of having failed to meet these expectations. Accordingly, Georg Simmel has pointed to the deep social roots of shame, also emphasizing the wide spectrum of occasions for feelings of shame, ranging from "an ill-fitting suit to grave moral turpitude" (Simmel 2000, p. 140; translation from German by the author). For him, shame occurs in all cases of involuntary exposure, of an "exaggeration of the self" (Simmel 2000, p. 142; translation from German by the author), in which not only a violation of moral norms but also of aesthetic, bodily, or cultural expectations becomes visible for others-at this point, the social and the inner worlds are indistinguishable, for the feeling of shame testifies to a highly internalized system of norms and expectations and thus fundamentally affects "the whole and normative conception of oneself" (Simmel 2000, p. 142; translation from German by the author).

That said, to what extent does such a notion of shame also help to distinguish between shame and embarrassment? Based on the sociological perspective, any difference cannot be found at the level of the feelings themselves, but rather in diverging social courses of action-an approach already suggested by Krawczak, who considered it more promising to focus on the "contextual features that are more directly linked to the situation engendering the emotional experience" (Krawczak 2018, p. 457). Accordingly, feelings of shame are always engendered by the question of how the public would judge one's appearance, one's deeds, one's misconduct — even if this judgment is only an imaginary one (Tangney and Dearing 2002, p. 18). Although the public is the crucial frame of reference for these kinds of feelings, it is often socially expected to feel shame privately-withdrawal from the social environment is a well-known consequence of the feeling of shame (see also Silfver-Kuhalampi et al. 2013, p. 393). 
This brings us to what I see as a small but important difference between shame and embarrassment: the role of the public as bystander. In embarrassing situations, the public is necessarily present-one cannot be embarrassed by oneself-and what is at stake in such situations is the whole impression a person wants to convey, which is constantly in danger of being compromised by moments of carelessness, by small mishaps, by awkward appearances to others. Thus, the whole range of face-work that Erving Goffman (1959) analysed so thoroughly ultimately aims at avoiding embarrassmentwhether it is appropriate dress, irony as a means of shielding the inner and vulnerable self from the social environment, or all the elements of stable facades (e.g., bookshelves, name tags, or seating arrangements) that support the proper presentation of the self in public. Conversely, embarrassment occurs when these multiple techniques of buffering the "naked self" (for the conceptual mapping of nakedness in this context see Kövecses 2000, p. 33) fail and one's physicality or corporeality (which includes sexuality, impulsivity, affectivity) becomes visible to the public in unanticipated and unintended ways. In this case, the selfpresentation one wants to give does not match the self-presentation one actually produces, and blushing is the most visible symptom of this mismatch.

However, if the bystanders are attentive and empathetic enough, in situations of embarrassment one can often observe a joint interactional effort to overcome the situation, as everyone knows that the discrepancy between intended and actually produced selfexpression is one of the most unpleasant feelings. Therefore, it is not surprising that social life has some repair mechanisms for these kinds of situations. Let us illustrate these common repair mechanisms with a small example, namely a glass of water that I spill all over the table during a lecture. When this happens, there are several interactive ways to deal with this situation. We could all overlook it and pretend that nothing happened; the host could apologize for putting the glass too close to my body; I could try to reinterpret the situation as an example I just used to illustrate what embarrassment is; I could ironically relate the situation to my professional self-description by saying, for example, that my dry lecture can take a little animation.

In all these cases, my mishap is socially redefined and reframed, and this leads us to the most important difference between shame and embarrassment as it will be brought to bear in the following: while "shame" denotes an individual and isolated feeling, and as such is even socially expected ("You should be ashamed!", "Shame on you!"), in the case of "embarrassment", it often remains unclear whether this term refers (only) to one's own (mis)behaviour or rather to a situation that is collectively perceived as embarrassing. Elias even understands this difference as a categorical one: for him, embarrassment refers to the misbehaviour of others, but still leads to one's own discomfort. Simmel (2000, p. 140) also points out that the tactlessness of others causes a feeling of unease. This difference need not be adopted in all its consequences, but it does indicate that coping with such a situation requires joint interactional effort because all parties are-literally-affected. This is an aspect that Taylor (1985) once tried to capture with the somewhat curious assumption that embarrassment is "contagious". Embarrassment, in this sense, always bears traits of what might be called, in an unusual sense, Fremdscham: the situation is perceived and accepted as a common challenge, even if the sources of the discomfort are to be located outside of oneself.

\section{Decomposing the Presentation of Self-Reality TV}

Let us now look at what happens to repair mechanisms in so-called "reality TV", keeping present what has been said about the joint interactional effort to overcome situations of embarrassment. Wife Swap is a series that first aired in the UK in 2003 and was adapted for the German television market and broadcasted by RTL under the title Frauentausch in the same year. The storyline is largely the same: two women from different social, cultural and economic backgrounds "swap" their families for a week and are filmed continuously during their swap. The footage is then edited, montaged, cut and rearranged to highlight the social incompatibility of the protagonists using simple but 
effective dramaturgical devices. The social conflicts over nutrition, upbringing, culture, education, hygiene, etc., already fueled by the editorial staff on location, are presented as a clash of social "lifestyles", being rather "a battle that is always already won" (Piper 2004, p. 276). Through a haphazard arrangement of different scenes, zooming, repetitive loops, ironically dramatizing music, mocking digital animations, sarcastic off-screen comments, and voice-over narration (see Walters 2006), the woman from the lower social class-mostly working class-is offensively devalued, while the lifestyle, preferences, and choices of her middle-class antagonist appear in a much brighter light (for a more detailed case study of a single episode see Lyle (2008); in what follows, however, the focus is not on such a case study, but on the general mechanisms that decompose the presentation of self; even though no sequence analysis is carried out here, the mechanisms described can be best understood with the popular episode no. 281: "Birgit und Nadine", taken from the German adaptation Frauentausch).

The never-changing script of this type of TV show has already been analysed by a number of profound approaches, mostly from a Bourdieuvian or Foucauldian perspective, focusing on the stereotypical "making" of the underclass (Lyle 2008; Wood and Skeggs 2008; Hirdman 2016), especially of working-class women (Fairclough 2004), and the neoliberal technologies of the self (Skeggs 2004) that are driven by these kinds of shows, including also the class-related reception of these shows (Skeggs et al. 2008). Our question, however, is more basic as it seeks first to reconstruct the actual process of decomposing the selfrepresentation in such TV shows, and to this end it might be helpful not to overload the analysis with too many theoretical references and presuppositions at the outset.

It is easy to see that the whole arrangement of Wife Swap contains embarrassing situations in nuce: basically, the little sins of everyday life, the mundane, the ordinary come out-someone eats unhealthy, smokes too much, is dressed inappropriately, has a reading disability, mispronounces something, classifies something in a wrong way. This everyday sphere is also precisely the sphere of embarrassment in the sense explained above because if it were a matter of serious misconduct-for example, things that are explicitly forbidden - the big brother of embarrassment (and shame), namely guilt, would determine the situation.

However, Wife Swap also contains the more detailed ingredients of embarrassment that we discussed above with reference to Elias, Simmel, and Goffman:

- first, we have "the body", we have corporeality, affectivity, impulsivity, disgust; most of the conflicts presented revolve around body-related issues such as organic food vs. fast food, smoking vs. nosmoking, and all aspects of personal hygiene-it is unlikely to watch a season of Wife Swap without zooming in on an overflowing ashtray at some point.

- $\quad$ second, we have "the public", or, more precisely, the television public, to which this physicality, affectivity, impulsivity is exposed.

- and third, we have "self-presentation", that is, the effort of the portrayed actor to assemble all these body-related attitudes and preferences into a consistent whole, and thus present his everyday self to the public in a decent and dignified manner.

If we look at Wife Swap, we see that the publicly recognizable self-presentation of the actor in question fails completely; but why does it fail, and not sometimes, not randomly, but almost always and absolutely reliably? It is simply because the repair mechanisms of embarrassing situations mentioned at the beginning are deliberately over-ridden by these TV shows, for any externally or self-staged overcoming of embarrassing moments or situations is undermined. As a TV viewer, one obviously has no means of intervening in the situation, i.e., the viewer drops out as a potential repair agent. Even more striking, however, is that even the actor portrayed is no longer the "producer" of his public self-image; he merely supplies the material. The actual producer or creator is the already mentioned technical, dramaturgical and narrative means of staging, especially the highlighting of actions or objects that directly contradict the actor's intention to present himself in a decent way (e.g., the overflowing ashtray). That is, the actors are constantly deprived of the means 
of their public expression; and the pseudo-documentary character pretends at the same time that the actors show themselves in all their naturalness, their authenticity, their reality.

Now, this description does not answer the question of why we as viewers actually torture ourselves with such television formats. This willingness is actually all the more surprising against the backdrop of what has been said so far: situations that causes embarrassment are in themselves something that people try to avoid at all costs in everyday life. In the case of reality TV, this is compounded by the fact that the usual repair mechanisms for embarrassment are also eliminated, and this fact should actually make such situations even more unbearable. However, if we rely on the working definition of shame and embarrassment I proposed in the first chapter, there might be an explanation for bearing the unbearable: the decomposition of self-representation as performed in Wife Swap turns out to be an attractive means of affectively stabilized self-assurance of the viewer, that his own socio-moral grammar works properly, and this effect is achieved only when embarrassment is attributed not to situations, but to persons, and then merges into an unfulfilled expectation of individual shame.

Let us discuss this multi-stage process in detail, highlighting the attributional shifts from embarrassment to shame to so-called "Fremdscham" / vicarious embarrassment":

(1) embarrassment is not perceived or attributed as a social issue, but as an individual misbehaviour;

(2) there is no concerted effort to overcome this situation, i.e., the public either remains passive (the TV-audience) or-like the editorial staff-tries to provoke an even greater discrepancy between intended and achieved self-presentation;

(3) actor is deprived of any chance to regain control over his self-presentation; instead, the mismatch between the intended impression and the impression actually created is constantly reinforced

(4) for lack of interactional effort, social feedback, or dramaturgical control, the actor appears as someone who cannot even be ashamed of his bad impression, and shame is, in a sense, the last option to act in a socially appropriate way when all other options have dwindled;

(5) the viewer is given a chance to reassure himself that his own socio-moral grammar is still functioning; and he does so by feeling vicariously embarrassed or "Fremdscham", but in a safe and distant space and without the risk of physical exposure-it is quite unlikely that someone who is vicariously embarrassed will blush alone in front of the television;

(6) the viewer shares his or her experience of "vicarious embarrassment" or "Fremdscham" with others, who then confirm that the incident is indeed "cringy".

\section{Accepted and Unaccepted Deviations in Flexible Normalism}

However, this multi-stage process cannot yet answer the question under which social conditions this form of "negative", shame-mediated self-assurance is likely to occur at all. In previous research, this question has been answered primarily in two rather incongruent directions. The first explanation is offered by authors such as Kotsko, who-as noted in the beginning-focus on the awkward turn since the 1970s. From Kotsko's perspective, the interest in awkward comedy can be traced back to a general uncertainty about the validity of social norms in Post-Fordist times (see Kotsko 2010, pp. 15-22). After the nuclear family with its clear, gender-related distribution of roles has lost its hegemonic position, normative orientation becomes stuck between a "no more" and a "not yet", and this gap is filled with all forms of awkward self-representation. This basic assumption of normative uncertainty is essential to our question, for without such uncertainty, it would remain unclear why individuals strive for affective self-assurance in the first place, as we have just reconstructed it.

For the second type of explanation, Wife Swap is just another media exercise in naturalizing and individualizing social inequality by disguising it as a matter of arbitrary lifestyle and resolving it into a matter of taste. Moreover, this classic interpretation, which 
finds its main theoretical reference in Pierre Bourdieu's Distinction (Bourdieu 1985), is far from wrong. As has often been shown, the whole arrangement of Wife Swap is designed to represent different social, cultural, and economic opportunities in terms of bad choices and wrong lifestyles.

However, do we see the whole picture through these approaches? In what follows, I will try to explain both the absence and the restabilization of normative orientation, and this attempt builds on the distinction between acceptable and unacceptable deviations from the "normal." In the background of this argument is an observation by Jürgen Link, who views contemporary Western societies as flexible normalist societies (Link 1996, 2004). "Normalism" refers to a mode of social orientation that can be illustrated by a simple and everyday operation: googling on the Internet what is "normal", e.g., how many sexual partners a person aged 32 has had on average or how many litres of pure alcohol the average German consumes per year. Thus_-and this is the crucial difference-those seeking social orientation no longer orient themselves to prescriptive norms, no longer to "right" or "wrong" behaviour, but to empirically determined average values. Such a normalistic orientation takes on a flexible shape when the boundaries of "normality" are experienced as contingent and thus open to negotiation and variation. In such a flexible normalism, Link argues, a certain degree of deviation from the statistical average is itself qualified as normal and socially expected, and often a certain degree of deviation even appears desirable, as the current discourse on "singularity" (Reckwitz 2020) also shows-no one likes to be "average" and nothing else.

On the other hand, even and especially under these "flexible" conditions, there is an urgent need to mark more precisely the boundaries of what is no longer considered a normal deviation. I think that this distinction is omnipresent in Wife Swap, as both "normal" and "non-normal" deviations are shown and demarcated from each other all the time. Accordingly, not only is there the party that is offensively devalued, but there is also the positive counterpart of "normal deviance", for example, the queer couple who eats a vegan diet, or the fully tattooed candidate who is open to alternative forms of relationships.

Significantly, this difference between acceptable and unacceptable deviation can be seen not only in Wife Swap, but also in other reality formats such as I'm a celebrity-Get me out of here! The most popular characters in these shows represent exactly what I have called "normal deviation". In the German version of I'm a celebrity-Get me out of here! (Ich bin ein Star, holt mich hier raus!), gay ex-boyband members, travesty artists, strippers or erotic models, among others, are at the top of the list. These successful candidates are not "normal" in the sense of a statistical average, but they are normal in the sense of a "normal deviation"; and interestingly enough, it is even the case that actors like the very average "Honey", a candidate of season 11, are simply devalued because they are not "authentic" and "individual" enough.

Seen in this light, Wife Swap is indeed structured by a "middle class gaze" (Lyle 2008) exercised through "symbolic violence" (Skeggs 2000, p. 129) against "the working class as abject other" (Lyle 2008, p. 323). With respect to the diagnosis of flexible normalism, however, Wife Swap et al. is not only about devaluation and humiliation, but also about orientation. The point at which the horizontal openness to "normal" deviations turns into a vertical orientation can be clearly marked in our multi-stage process: this peripety takes place in stage four, where the decomposition of self-presentation escalates into moral resentment and the expectation of being ashamed, transforming-with a distinction by Sighard Neckel (1991, p. 52)—social shame in moral shame. In Wife Swap, the child is often the crucial medium that enables a distinction between acceptable and unacceptable deviance, for then differences in "lifestyle" suddenly appear as moral problems of responsible parenting, usually culminating in the question: "How dare you feed your child fast food?" (on the relationship between class-related shame and family life in reality TV, see Ferguson 2010). In this way, the middle class manages to locate itself in the current flexible normality without being submerged in it. Further analysis would have to show whether programmes that do not have a downward demarcation also fulfill a similar function. The 
portrayal of "rich kids", as found in "Simple Life" or "Die Geissens", for example, usually focuses on the habitus of the "nouveau riche" which is contrasted with the lives of hard-working people. On closer inspection, however, a self-assurance of the middle classes can be found here as well, which is also gained primarily through questions of taste: the disgust of the "rich kids" is in a way itself disgusting because it is not articulated as a well-tempered judgement of taste that also takes into account the necessities of everyday life. Rather, it is expressed in an exaggerated, chichi, spoiled manner that reveals a lack of cultural capital. Thus, again, cringe seems to be an affective and effective way of making the distinction between normal and non-normal deviance. I think that can, to some extent, answer the question of why we are willing to put up with intolerable television shows. It is comic relief in the literal sense, and at the same time social relief in a world of deviance.

\section{Fremdscham, Vicarious Embarrassment, and Cringe}

Now, how do these findings relate to the questions I posed at the outset, particularly regarding the re-differentiation of what is actually meant by "(vicarious) embarrassment," "Fremdscham," and "cringe"? Obviously, Wife Swap has vanished from the screen, but "cringe" is still on. Shows and movies like Curb Your Enthusiasm, Pastewka, Borat, Jerks, The Office, Stromberg, My New Best Friend, Mein Neuer Freund, and many more are commonly ascribed to a genre known as "cringe comedy", and the general popularity of the term "cringe" - probably also due to an erratically tweeting ex-president-continues to grow in a variety of contexts. Now, is the same mechanism at work in these broadcasts that was just analysed in the example of Wife Swap, or is the cringe evoked in these formats of a different kind?

This question leads us back to the assumption already made in the introduction, that "Fremdscham" and "vicarious embarrassment" are rather unsuitable translations of or synonyms for "cringe", as their connotative dimensions and attributional logics differs significantly. This assessment can now be spelled out more clearly. "Fremdscham" and "vicarious embarrassment" in the literal sense presuppose that the triggers of this feeling are successfully identified-otherwise the vicarious embarrassment would have no object at all to take its place, and "Fremdscham" would also lack a point of reference. However, we have now seen that such identification requires a complex multi-stage process (and multi-staging process!), that supports or rather imposes the "right" attributions. "Cringe", however, merely refers to a physical reaction that is open to interpretation and whose actual triggers remain obscure. In this sense, "cringe" implies different directions of attribution: is my discomfort based on the impossibility of intervening in an embarrassing situation? Is it a result of the fact that conventional personal attributions fail because of the complexity or the inner dynamics of the situation being portrayed? Who actually is embarrassed by whom? Is my own everyday behaviour really that different from what I just perceive as cringeworthy? Last but not least: is my reaction at all appropriate to the situation presented, or does it not rather show my own uptightness or even resentment?

Against the background of these considerations, it should be clear that the explanatory claim that arises from our analysis of Wife Swap is severely limited. In shows like this one, the failures are so exaggerated and overdrawn that an openness for multiple and different attributions is blocked from the outset. Nevertheless, if we are to follow the multi-stage process we outlined above here, the cringe humour of The Office, Curb Your Enthusiasm, Borat, etc., already irritates and undermines the first stage of this process: the prototypical situation of cringe comedy is not broken down to personal shortcomings and clear responsibilities, but performs a various interplay between moments of awkward behaviour, failing self-presentation, mutually reinforcing misunderstandings, overshooting reactions, misguided attempts at appeasement, and much more-it remains at a stage where it is unclear and ambiguous who can be held responsible for the discomfort because the situation is too complex and multi-layered to reduce it to single acts of misconduct.

It seems to me that the formats mentioned-Curb your enthusiasm, Borat, The Office, etc.- owe their popularity to this variety of possible attributions. It may even be the 
case that some shows focus on certain nuances of this variety: in Borat, for example, the sources of discomfort often remain unclear and can no longer be reconstructed in terms of individual failure. Consider the scene in which Borat has a conversation with female American feminists (retrieved 26 August 2021, from https:/ / www.youtube.com/watch? $\mathrm{v}=\mathrm{mcO} 4 \mathrm{GopVIN} 4$ ). Here, the viewer is continuously prevented from identifying and isolating the actual sources of his cringe: Is it the "colonial" representation of Kazakh culture in general? Is it the fact that this representation is given by an-alleged-Kazakh himself? Is it the clumsy way in which Borat tries to elicit information from feminist women about-of all people-Pamela Anderson? Is it the innocent-looking directness with which Borat reproduces and enacts sexist-based expectations and phrases ("give me a smile!"; "Pussycat!")? Is it the lack of humour on the part of the women interviewed, who oscillate indecisively between pedagogical patience and horrified rejection? Or is it-and here the viewer is increasingly thrown back on his own interpretative schemes-the fact that the accusation of a lack of humour is still a promising means of males to stabilize traditional gender images?

Drawing on our working definition of shame and embarrassment and our analysis of Wife Swap, these formats consequently irritate the attributions that have already been made both in the case of "Fremdscham" and in the case of "vicarious embarrassment". Because one is left in the dark about the sources, triggers, and dynamics of the embarrassing situation, it is no longer possible to address shame to anyone in particular. When there is no one to be ashamed of, even the term "vicarious embarrassment" no longer has an object to which it could refer.

However, does this inability to reliably identify and attribute the triggers of cringe also affect our distinction between acceptable and unacceptable deviations and the diagnosis of flexible normalism? It seems to me that this type of cringe also plays on the borderline between acceptable and unacceptable deviations within flexible normalism, but this happens rather in the way of scrupulous self-questioning. Here, Kotsko's observation that the "awkward turn" in comedy gleefully explores the interactional and status insecurities of the white, heterosexual middle-class male in the post-Fordist age (on the relationship between status and shame, see Neckel 1991) can be further differentiated by our basic distinction. Moreover, David Brent, Bernd Stromberg, Larry David or Bastian Pastewka are children of flexible normalism; they always oscillate between forgivable idiosyncrasies and rule violation, thus sounding out the possible extent of acceptable deviations.

Compared to Wife Swap, however, three things are particularly striking: first, the burden of discriminating between acceptable and unacceptable deviations is left to the viewer; second, the clumsy advances, the weak jokes, the little vulgarities, the distorted self-images and the attempts to rationalize one's own behavior are built far too close to the everyday experience of white-collar workplaces (see Kotsko 2010, pp. 25-38). This eliminates the possibility of delegating the unacceptable part of deviations to an "abject other" (Lyle 2008, p. 323) — the struggles of flexible normalism are fought here within the middle classes. Thirdly, the documentary style of filmmaking is realised in an entirely different way: Wife Swap shows real people in fictional, scripted situations, but at the same time parasitically benefits from the "old" currency of documentary-truth and authenticity-as the documentary style itself never becomes part of the action. Conversely, The Office or Stromberg show fictional, scripted people in (approximately) real situations, and-as Middleton has shown at length (Middleton 2014, pp. 140-70) — the mock documentary style offers "no stable point of identification" (Middleton 2014, p. 5). Especially in Stromberg, the German version of The Office, the overt use of the camera leads to reflexive loops that one looks for in vain in Wife Swap. Finally, these loops even enable the "fictional" Stromberg to present himself as a subject resistant to social attributions-a recovery of the dramaturgical means of self-representation that is systematically denied to the "real" actors of Wife Swap: "I am not available for such a perception of myself." (retrieved 26 August 2021, from https: / / www.facebook.com/watch/?v=332642391743083\&ref=sharing, 02:14; translation from German by the author). 


\section{Summary and Outlook}

This paper approached the phenomenon of cringe via the sociological distinction between embarrassment and shame. This approach was based primarily on two considerations: firstly, the distinction between shame and embarrassment should be used to more precisely circumscribe the phenomenal area in which cringe is located: it is not about violating explicit norms, but rather about the mismatch between the intended self-presentation and the self-presentation actually created. However, in contrast to some psychological approaches, we have not located the difference between embarrassment and shame on the level of essential feelings, but on the level of social interaction orders and corresponding expectations: "embarrassment" is closely related to a public that is present and tries actively to narrow the gap between intended and achieved self-presentation. Shame, on the other hand, is expected to be felt alone.

Secondly, based on this distinction, it was then possible to address the problems associated with common translations or synonyms for "cringe": "Fremdscham" and "vicarious embarrassment". The attributive logic of these terms has been exemplified by a closer look at the series Wife Swap. In this case, cringe turns out to be a means of affectively stabilized self-assurance of the viewer, clearly resolving embarrassing situations in attributions of personal failure. Moreover, cringe in this context makes it easier to draw the line between acceptable and unacceptable deviations more reliably, as the decomposition of selfrepresentation is increased to the point of moral discredit. For this type of cringe, "vicarious embarrassment" and "Fremdscham" might indeed be adequate synonyms and translations. Without taking the risk of a failed presentation of self, the viewer fulfils the social expectation to be ashamed instead of another who is apparently incapable of this elementary social impulse-and thereby assures himself of his own status as a moral subject.

In the last chapter, however, we saw that the cringe evoked in formats like Borat or Stromberg is of a different nature. There, the interactional tension is not resolved step by step as in the multi-stage process of Wife Swap but remains in its earliest stage so that a successful attribution of "cringe" to unit acts of failure is blocked from the very beginning. Even more, the attempt to reliably assign the triggers is thwarted again and again so that at some point, the viewer is thrown back on his own standards of judgement. In this case, cringe is an affective state that is located on the borderline of acceptable and unacceptable deviations and literally embodies the contingency of this distinction.

For further research on this phenomenon, it could be particularly interesting to see whether these two shades of cringe could lead to "cringeworthy" constellations of a new kind, being accelerated through the instant mode of social media communication. Here, we have only taken a look at the shades of cringe as they can be found in classical mass media constellations. However, how does this editorially produced type of cringe relate to all the "cringeworthy" memes and GIFs that are sent around the globe today? It seems to me that the full range of cringe, as we have worked it out here, also unfolds in this context; it moves between orientation and irritation. The middle-class gaze, however, could dissolve more and more into different value orientations, as memes and GIFs become iconic in such a fast, opaque and unpredictable way that they can hardly be located in terms of social structure anymore. At the same time, they often become particular subcultural identifiers that are hardly understood beyond the respective community. In the political field, meanwhile, a specific dynamic of cringe might already be built into the basic communication structure: on the one hand, there are the high demands for politically correct behaviour; on the other hand, there is the increased likelihood of being caught failing to meet these demands-and in between, populist attempts to close this gap by renouncing all political decency and putting open aggression in its place, with the aim of expanding the field of acceptable deviation further and further. A last question that deserves deeper clarification is whether and to what extent the initially media-bound expression "cringe" is increasingly also applied to classic interaction situations. In this case, the distinction between (vicarious) embarrassment and cringe would have to be revisited once again. As we have seen, embarrassing situations in its sociological understanding tend to be overcome through 
joint effort and mutual facework (Goffman 1959). Despite its reflexive and multidirectional openness, however, cringe still denotes a passive emotional state. If this passive trait is transferred to situations that actually require active coping, this could profoundly change the social order of such an interaction. Take up the above example again: during a lecture, the speaker spills a glass of water over the table, and while everyone is cringing, it slowly runs into the projector. It is not only here that the "cards of cringe" seem to be reshuffled once again.

Funding: This research received no external funding. The APC was funded by Volkswagen Foundation.

Institutional Review Board Statement: Not applicable.

Informed Consent Statement: Not applicable.

Data Availability Statement: Not applicable.

Conflicts of Interest: The author declares no conflict of interest.

\section{References}

Babcock, Mary K., and John Sabini. 1990. On differentiating embarrassment from shame. European Journal of Social Psychology 20: 151-69. [CrossRef]

Bourdieu, Pierre. 1985. Distinction. A Social Critique of the Judgment of Taste. Cambridge: Harvard University Press.

Crozier, W. Ray. 2014. Differentiating Shame from Embarrassment. Emotion Review 6: 269-76. [CrossRef]

Elias, Norbert. 2012. On the Process of Civilisation. Sociogenetic and Psychogenetic Investigations. Translated by Edmund Jephcott. with some notes and corrections by the author. Dublin: University College Dublin Press.

Fairclough, Kirsty. 2004. Women's work? Wife Swap and the reality problem. Feminist Media Studies 4: $344-47$.

Ferguson, Galit. 2010. The Family on Reality Television: Who's Shaming Whom? Television E New Media 11: 87-104.

Goffman, Erving. 1959. The Presentation of Self in Everyday Life. New York: The Overlook Press.

Hirdman, Anja. 2016. The passion of mediated shame. Affective reactivity and classed otherness in reality TV. European Journal of Cultural Studies 19: 283-96. [CrossRef]

Kotsko, Adam. 2010. Awkwardness. An Essay. Winchester: O-books.

Kövecses, Zoltan. 2000. Metaphor and Emotion. Language, Culture, and Body in Human Feeling. Cambridge: Cambridge University Press.

Krawczak, Karolina. 2018. Reconstructing social emotions across languages and cultures. A multifactorial account of the adjectival profiling of shame in English, French, and Polish. Review of Cognitive Linguistics 16: 455-93. [CrossRef]

Lewis, Michael. 2008. Self-conscious emotions: Embarrassment, pride, shame and guilt. In Handbook of Emotions. Edited by Michael Lewis, Jeanette M. Haviland-Jones and Lisa Feldman Barrett. New York: Guilford Press, pp. 742-56.

Link, Jürgen. 1996. Versuch über den Normalismus. Wie Normalität Produziert Wird. Opladen: Westdeutscher Verlag.

Link, Jürgen. 2004. From the "Power of the Norm" to “Flexible Normalism": Considerations after Foucault. Translated by Mirko M. Hall. Cultural Critique 57: 14-32. [CrossRef]

Lyle, Samantha A. 2008. (Mis)recognition and the middle-class/bourgeois gaze. A case study of Wife Swap. Critical Discourse Studies 5: 319-30. [CrossRef]

Middleton, Jason. 2014. Documentary's Awkward Turn. Cringe Comedy and Media Spectatorship. New York: Routledge.

Neckel, Sighard. 1991. Status und Scham. Zur symbolischen Reproduktion sozialer Ungleichheit. Frankfurt: Campus.

Piper, Helen. 2004. Reality TV, Wife Swap and the drama of banality. Screen 45: 273-86. [CrossRef]

Reckwitz, Andreas. 2020. The Society of Singularities. Translated by Valentine A. Pakis. Cambridge: Polity Press.

Reddy, Vasudevi. 2008. How Infants Know Minds. Cambridge: Harvard University Press.

Sabini, John, Brian Garvey, and Amanda L. Hall. 2001. Shame and Embarrassment Revisited. Personality and Social Psychology Bulletin 27: 104-17. [CrossRef]

Scheff, Thomas J. 2000. Shame and the Social Bond: A Sociological Theory. Sociological Theory 18: 84-99. [CrossRef]

Silfver-Kuhalampi, Mia, Johnny J. R. Fontaine, Let Dillen, and Klaus R. Scherer. 2013. Cultural differences in the meaning of guilt and shame. In Components of Emotional Meaning. Edited by Johnny J. R. Fontaine, Klaus R. Scherer and Christiana Soriano. Oxford: Oxford University, pp. 388-96.

Simmel, Georg. 2000. Zur Psychologie der Scham. In Das Wesen der Materie nach Kant's Physischer Monadologie Abhandlungen 1882-84. Rezensionen 1883-901. Edited by Klaus Christian Köhnke. Simmel Gesamtausgabe in 24 Bänden, Bd. 1. Frankfurt: Suhrkamp, pp. 431-42.

Skeggs, Beverly. 2000. The appearance of class. Challenges in gay space. In Cultural Studies and the Working Class. Subject to Change. Edited by Munt Sally R. London: Cassell, pp. 120-50.

Skeggs, Beverly. 2004. Class, Self, Culture. London: Routledge.

Skeggs, Beverly, Nancy Thumim, and Helen Wood. 2008. "Oh goodness, I am watching reality TV": How methods make class in audience research. European Journal of Cultural Studies 11: 5-24. [CrossRef] 
Tangney, June Price, and Ronda L. Dearing. 2002. Shame and Guilt. New York: Guilford.

Taylor, Gabriele. 1985. Pride, Shame and Guilt: Emotions of Self-Assessment. Oxford: Clarendon.

Walters, James. 2006. "Emotional Blood on the Undusted Carpets". The Citizen as Subject in Wife Swap. Critical Survey 18: 51-64. [CrossRef]

Wood, Helen, and Beverly Skeggs. 2008. Spectacular morality: "Reality" television, individualisation and the remaking of the working class. In The Media and Social Theory. Edited by David Hesmondhalgh and Jason Toynbee. London: Routledge Taylor \& Francis Group, pp. 177-93. 